\title{
Contamination and risk of heavy metals in soils and sediments from a typical plastic waste recycling area in North China
}

\author{
Zhenwu Tang ${ }^{\mathrm{a}}$, Lianzhen Zhang ${ }^{\mathrm{a}}$, Qifei Huang ${ }^{\mathrm{b}, *}$, Yufei Yang ${ }^{\mathrm{b}}$, Zhiqiang Nie ${ }^{\mathrm{b}}$, \\ Jiali Cheng ${ }^{\mathrm{c}, * * k^{\prime}}$, Jun Yang ${ }^{\mathrm{d}}$, Yuwen Wang ${ }^{\mathrm{a}}$, Miao Chai ${ }^{\mathrm{a}}$ \\ a MOE Key Laboratory of Regional Energy and Environmental Systems Optimization, Environmental Research Academy, North China Electric Power Uni- \\ versity, Beijing 102206, China \\ ${ }^{\mathrm{b}}$ State Key Laboratory of Environmental Criteria and Risk Assessment, Chinese Research Academy of Environmental Sciences, Beijing 100012, China \\ ${ }^{\mathrm{c}}$ National Institute for Nutrition and Health, Chinese Center for Disease Control and Prevention, Beijing 100021, China \\ d Center for Environmental Remediation, Institute of Geographic Sciences and Natural Resources Research, Chinese Academy of Sciences, Beijing 100101, \\ China
}

\section{A R T I C L E I N F O}

\section{Article history:}

Received 7 May 2015

Received in revised form

4 August 2015

Accepted 6 August 2015

Available online 20 September 2015

Keywords:

Heavy metal

Pollution

Risks

Soils and sediments

Plastic waste recycling

\begin{abstract}
A B S T R A C T
Plastic wastes are increasingly being recycled in many countries. However, available information on the metals released into the environment during recycling processes is rare. In this study, the contamination features and risks of eight heavy metals in soils and sediments were investigated in Wen'an, a typical plastic recycling area in North China. The surface soils and sediments have suffered from moderate to high metal pollution and in particular, high $\mathrm{Cd}$ and $\mathrm{Hg}$ pollution. The mean concentrations of $\mathrm{Cd}$ and $\mathrm{Hg}$ were 0.355 and $0.408 \mathrm{mg} \mathrm{kg}^{-1}$, respectively, in the soils and 1.53 and $2.10 \mathrm{mg} \mathrm{kg}^{-1}$, respectively, in the sediments. The findings suggested that there is considerable to high potential ecological risks in more than half of the soils and high potential ecological risk in almost all sediments. Although the health risk levels from exposure to soil metals were acceptable for adults, the non-carcinogenic risks to local children exceeded the acceptable level. Source assessment indicated that heavy metals in soils and sediments were mainly derived from inputs from poorly controlled plastic waste recycling operations in this area. The results suggested that the risks associated with heavy metal pollution from plastic waste recycling should be of great concern.
\end{abstract}

(c) 2015 Elsevier Inc. All rights reserved.

\section{Introduction}

The quantities of end-of-life plastics from households and industries have increased markedly in recent decades (Thompson et al., 2009). Plastic waste treatment is becoming a vital task worldwide because these wastes are resistant to degradation and are leading to various environmental problems, including plastic pollution in the ocean (Rochman et al., 2013; Jambeck et al., 2015). In the past, plastic waste was usually landfilled together with municipal solid waste. Low sustainability, increasing cost and decreasing space for landfills are forcing consideration of alternative options for plastic waste disposal. Recycling has become the primary policy for treating plastic waste in many countries (Al-Salem

\footnotetext{
* Corresponding author. Fax: +861084913903.

*** Corresponding author. Fax: +861083157181.

E-mail addresses: zwtang@ncepu.edu.cn (Z. Tang),

446329773@qq.com (L. Zhang), huangqf@craes.org.cn (Q. Huang),

cqyyf@163.com (Y. Yang), niezq@craes.org.cn (Z. Nie),

jlcheng77@163.com (J. Cheng), yangj@igsnrr.ac.cn (J. Yang),

18810720592@163.com (Y. Wang), 15650798262@163.com (M. Chai).
}

et al., 2009; Hopewell et al., 2009). Material recycling is becoming the key disposal method for plastic waste in developing countries because of the relatively low investment and simple technology requirements, although energy recovery and chemical recycling are encouraged in some developed countries (Al-Salem et al., 2009; Hopewell et al., 2009).

Many plastic wastes contain or are contaminated with harmful chemicals. It was reported that the chemical ingredients of more than $50 \%$ of plastics are hazardous (Lithner et al., 2011). Some hazardous chemicals are also widely used as specific targeted additives in plastic products. For example, brominated organics and phthalate esters (PAEs) have been extensively applied in plastic products as flame retardants and plasticizers, respectively. These additives also include other flame retardants and plasticizers, pigments, stabilizers, and reinforcement components, which are composed of heavy metals or metal compounds (Dimitrakakis et al., 2009; Li and Shi, 2011; Nakashima et al., 2012; Rochman et al., 2013). In some products, the contents of these dangerous additives are high or extremely high (Morf et al., 2007; Dimitrakakis et al., 2009; Stenvall et al., 2013). For example, the upper concentration ranges of $\mathrm{Pb}$ and $\mathrm{Sb}$ were reported at 
$100-2000 \mathrm{mg} \mathrm{kg}^{-1}$ and $2-13 \mathrm{~g} \mathrm{~kg}^{-1}$, respectively, in the plastic fraction of waste electrical and electronic equipment (WEEE) (Morf et al., 2007). In addition, plastic wastes can potentially absorb various priority pollutants from the environment to some extent (Nakashima et al., 2012; Rochman et al., 2013). Hence, many toxicants could be released into the environment during the milling, washing and melt processing of material recycling of plastic wastes, especially with the rather primitive and crude facilities used.

Pollutant release from material recycling has not received much attention. Such contamination is traditionally undervalued perhaps because this recycling is only a mechanical process and is conducted at relatively low temperatures $\left(<300{ }^{\circ} \mathrm{C}\right.$ in the extrusion). Several studies have recently reported the emission of harmful compounds from material recycling processes. Dozens of volatile organic compounds were identified in the air and the workers suffered acute and chronic health risks in poly(acrylonitrile-butadiene styrene) (ABS) and polystyrene (PS) recycling workshops (Huang et al., 2013; He et al., 2015). High levels of polycyclic aromatic hydrocarbons and PAEs were also measured in the air from a polyvinyl chloride (PVC) plastic waste recycling plant (Tsai et al., 2009; He et al., 2015). Our previous research reported that high concentrations of polybrominated diphenyl ethers (PBDEs) occurred in the environment and in human hair in a plastic recycling area in China and their potential risks should be of great concern (Tang et al., 2014). Available information about the toxicant emissions and pollution characteristics from these processes is still rare.

The occurrence of material recycling of plastic waste by environmentally unfriendly and primitive technologies in developing countries, especially in Asia, Africa and Latin America, has increased in recent years (Pacheco et al., 2012; Huang et al., 2013; Yang and Buekens, 2014). In China, the total recycling of plastic wastes increased from 16.1 million tonnes in 2008 to 24.9 million tonnes in 2013; of the plastic recycled, primitive material recycling of plastic waste is common (Wei and Zhang, 2014). So far, little is known about the release of heavy metals into the environment in plastic waste recycling areas where primitive methods are used, and the potential ecological and human risks of heavy metals from such sites remain unknown. Using Wen'an, in northern China, as a case study for plastic waste recycling, the objectives of this study were to conduct a reconnaissance survey to investigate and characterize the level and risk of toxic metals in soils and sediments. The results will improve our understanding of the extent of heavy metal pollution caused by plastic waste recycling and provide information to plan risk management measures.

\section{Materials and methods}

\subsection{Study area}

Wen'an County, in northeast Hebei Province, China, has a population of 460,000 and an area of $1028 \mathrm{~km}^{2}$. The material recycling of plastic wastes has been practiced intensively in 101 villages in eight towns in Wen'an, the largest distribution center of material recycling of plastics in North China, employing nearly 100,000 people (Xu et al., 2010; Liu, 2011). These valuable materials have been reclaimed for more than 20 years in the village of Yincun, located in the central part of Zhaogezhuang, Wen'an. In the town of Daliu, next to Zhaogezhuang, intensive plastic waste recycling processes were also active for over a decade. The recycled wastes include ABS, PS, PVC, polyethylene (PE), polypropylene (PP), polyamide (PA), polycarbonate (PC) and others originating from both industrial and household waste. In Wen'an, recycling operations consist of collection, separation, milling, washing, agglutination, extrusion, quenching and granulation. It is worth noting that these processes were previously performed using crude techniques in family-run workshops in the residential districts. Previously, the processes were not controlled and gaseous and wastewater emissions were not treated. Since 2011, the crude recycling processes have ceased and have been prohibited by the local government. The recycling process of plastic wastes was concentrated at new industrial parks with strict pollution control in other area. In the area, the legacy of these previous recycling techniques, including environmental contamination, is still of concern.

\subsection{Field sampling}

Based on the sampling guide and methodologies recommended by Chinese Ministry of Environmental Protection (CMEP, 2010), 65 surface soil samples $(0-10 \mathrm{~cm})$ were collected from the typical sites in Zhaogezhuang and the adjacent Daliu in November 2011, with the area sampling pattern. All the sampling sites were selected on the basis of their separate representativeness of contaminated or uncontaminated soils. The site density of soil sampling was increased in Yincun, which has been the site of the longest-running continuous recycling activities in Wen'an. For comparison, 10 soil samples were collected at the same time from reference cropland, located approximately $3 \mathrm{~km}$ northeast of Yincun, which was less affected by the waste plastic recycling activities. The sampling locations are shown in Fig. 1. Each soil sample consisted of four sub-samples that were randomly taken from the surroundings of each site, pooled and homogenized to form a representative sample.

In November 2011, 30 surface sediments (the top $10 \mathrm{~cm}$ ) were collected from the Xiaobaihe River, the Renwen Canal and the Yincun Ditch, according to the Geochemical Survey Specification set by CGS (China Geological Survey) (2009). In Xiaobaihe River and Renwen Canal, the sediment samples were collected from the contact part of the riverbank and river water. Differently, the sediment samples were collected from the bottom of the Yincun Ditch, an intermittent-stream which has received the main wastewater from plastic recycling activities. No sediment was collected in the upper of Renwen Canal (Fig. 1) because of its longterm dry. The sampling sites of sediments were selected according to their possible contamination based on our professional judgments. In the present study, the collection of sediments is difficult to be corresponding to the soil sampling, as a result of the specific distributions of plastic waste recycling facilities in the area. All sediment samples were placed in polyethylene bags and transported to the laboratory.

\subsection{Sample analysis}

All soil and sediment samples were air-dried at room temperature, the coarse debris was removed and samples were ground using a mortar and pestle and passed through a 100-mesh nylon sieve. Metal concentrations of the samples were measured at the Institute of Geophysical and Geochemical Exploration, Chinese Academy of Geological Sciences, which is certified by the China National Accreditation Board for laboratories. The results met the accuracy demanded by the China State Bureau of Technical Supervision. The methods of metal extraction and analysis were established by the institute (Yang et al., 2009). The details are described in the Supporting information.

\subsection{Geoaccumulation index}

In this study, the geoaccumulation index $\left(I_{\text {geo }}\right)$ has been used to evaluate the pollution level of heavy metals in soils and sediments. 


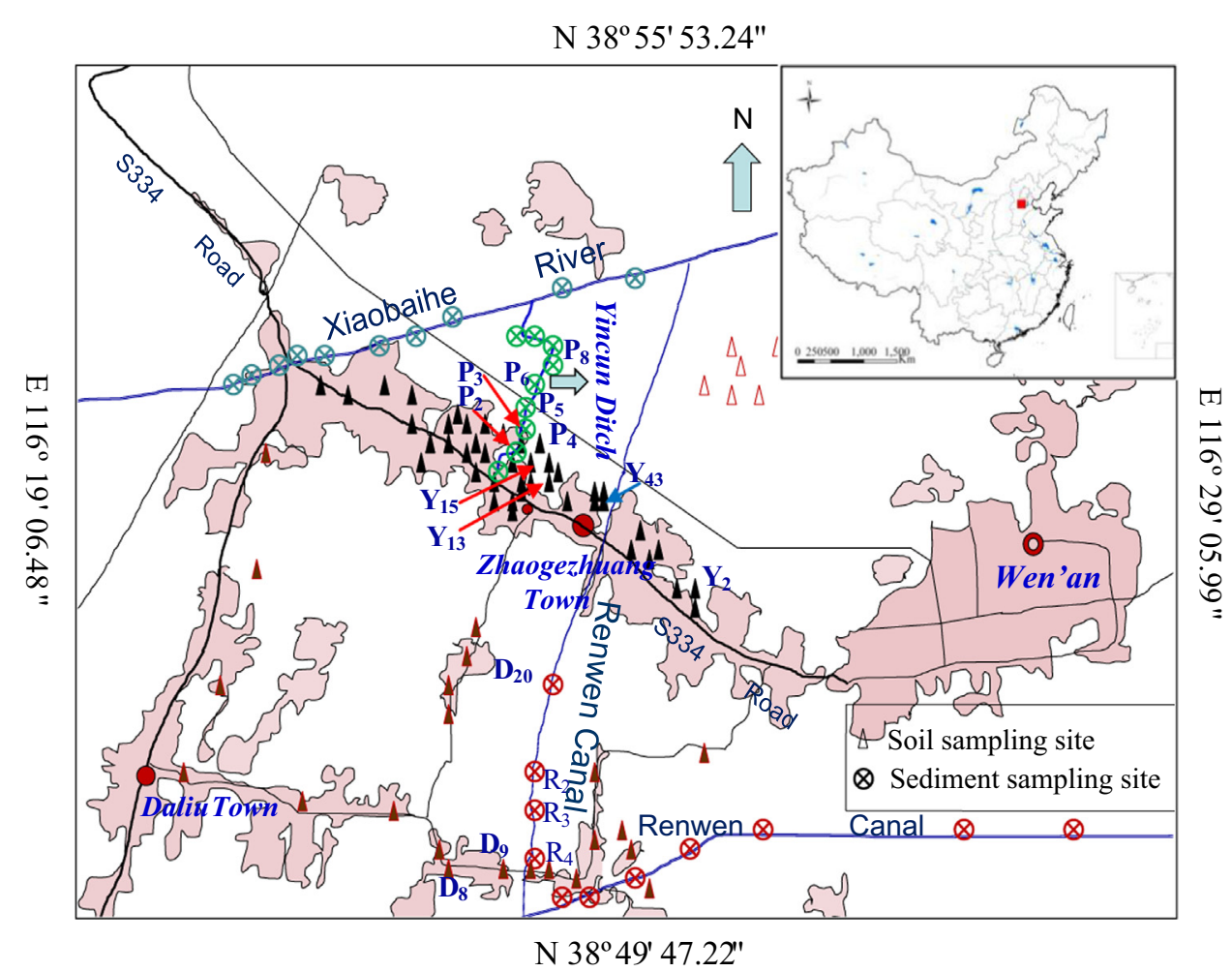

Fig. 1. Map of the soil and sediment sampling sites in Wen'an, northern China.

Table 1

Summary of heavy metal concentrations, with basic statistical parameters, for the soils and sediments collected from a plastic waste recycling area.

\begin{tabular}{|c|c|c|c|c|c|c|c|c|c|c|}
\hline & & & As $\left(\mu g g^{-1}\right)$ & $\mathbf{C d}\left(\operatorname{ng~g~}^{-1}\right)$ & $\mathbf{C r}\left(\mu \mathrm{g} \mathrm{g}^{-1}\right)$ & $\mathbf{C u}\left(\mu \mathrm{g}^{-1}\right)$ & $\mathbf{H g}\left(\mathrm{ng} \mathrm{g}^{-1}\right)$ & $\mathbf{P b}\left(\mu g g^{-1}\right)$ & $\mathbf{S b}\left(\mu \mathrm{g} \mathrm{g}^{-1}\right)$ & $\mathbf{Z n}\left(\mu \mathrm{g} \mathrm{g}^{-1}\right)$ \\
\hline \multirow[t]{12}{*}{ Soils } & \multirow[t]{3}{*}{ Zhaogezhuang $(n=43)$} & Range & $7.20-15.8$ & $118-2740$ & $69.0-120$ & $17.0-255$ & $27.0-14,450$ & $18.0-210$ & $1.00-18.3$ & $52.0-956$ \\
\hline & & Mean \pm SD & $10.6 \pm 1.80$ & $418 \pm 547$ & $90.7 \pm 13.2$ & $41.2 \pm 46.8$ & $603 \pm 2224$ & $40.4 \pm 35.5$ & $3.10 \pm 3.80$ & $120 \pm 146$ \\
\hline & & CV/Skewness & $0.171 / 0.460$ & $1.31 / 3.19$ & $0.146 / 0.641$ & $1.13 / 3.95$ & $3.69 / 6.05$ & $0.880 / 3.30$ & $1.25 / 3.12$ & $1.22 / 4.98$ \\
\hline & \multirow[t]{3}{*}{ Daliu $(n=22)$} & Range & $7.40-14.9$ & 116-1912 & $76.0-195$ & $17.0-205$ & $19.0-1750$ & $17.0-589$ & $0.80-33.3$ & $50.0-526$ \\
\hline & & Mean \pm SD & $10.7 \pm 1.80$ & $337 \pm 398$ & $100 \pm 26.7$ & $45.5 \pm 48.0$ & $211 \pm 435$ & $94.0 \pm 134$ & $3.6 \pm 6.90$ & $141 \pm 130$ \\
\hline & & CV/Skewness & $0.170 / 0.552$ & $1.18 / 3.40$ & $0.267 / 2.34$ & $1.05 / 2.59$ & $2.06 / 2.91$ & $1.42 / 2.82$ & $1.92 / 4.23$ & $0.924 / 1.95$ \\
\hline & \multirow[t]{3}{*}{ Reference area $(n=10)$} & Range & $9.60-13.7$ & 156-203 & $81.0-95.0$ & $18.0-34.0$ & 34.5-1935 & $21.0-29.0$ & $1.00-1.80$ & $62.0-81.0$ \\
\hline & & Mean \pm SD & $11.2 \pm 1.20$ & $180 \pm 18.6$ & $87.5 \pm 4.20$ & $22.1 \pm 4.50$ & $78.1 \pm 57.7$ & $23.4 \pm 2.20$ & $1.10 \pm 0.30$ & $69.5 \pm 6.40$ \\
\hline & & CV/Skewness & $0.111 / 0.728$ & $0.103 /-0.165$ & $0.048 / 0.249$ & $0.203 / 2.42$ & $0.739 / 1.69$ & $0.095 / 1.95$ & $0.225 / 2.58$ & $0.092 / 0.517$ \\
\hline & \multirow{3}{*}{$\begin{array}{l}\text { Background values }{ }^{a} \\
\text { Chinese soil guidelines }\end{array}$} & & 13.6 & 94.0 & 68.3 & 21.8 & 36.0 & 21.5 & 1.22 & 78.4 \\
\hline & & I & 15.0 & 200 & 90 & 35 & 150 & 35 & & 100 \\
\hline & & II & 30.0 & 300 & 200 & 100 & 500 & 300 & - & 250 \\
\hline \multirow[t]{11}{*}{ Sediments } & \multirow[t]{3}{*}{ Xiaobaihe River $(n=10)$} & Range & $6.20-14.1$ & $139-1570$ & $75.0-189$ & $23.0-96.0$ & $31.5-2550$ & $22.0-87.0$ & $1.40-8.70$ & $61.0-592$ \\
\hline & & Mean \pm SD & $8.90 \pm 2.30$ & $376 \pm 428$ & $110 \pm 32.2$ & $37.2 \pm 21.6$ & $320 \pm 786$ & $33.2 \pm 19.3$ & $2.70 \pm 2.20$ & $157 \pm 157$ \\
\hline & & CV/Skewness & $0.261 / 1.36$ & $1.14 / 2.95$ & $0.293 / 1.89$ & $0.579 / 2.71$ & $2.46 / 3.12$ & $0.581 / 2.94$ & $0.823 / 2.62$ & $0.995 / 2.88$ \\
\hline & \multirow[t]{3}{*}{ Renwen Canal $(n=11)$} & Range & $3.30-10.3$ & $121-5492$ & $60.0-130$ & 22.0-199 & $24.5-908$ & $17.0-123$ & $1.30-9.60$ & $57.0-257$ \\
\hline & & Mean \pm SD & $6.70 \pm 2.40$ & $1111 \pm 1740$ & $89.1 \pm 18.4$ & $58.4 \pm 51.8$ & $204 \pm 285$ & $50.3 \pm 34.9$ & $3.90 \pm 3.10$ & $134 \pm 80.4$ \\
\hline & & CV/Skewness & $0.351 / 0.134$ & $1.57 / 2.14$ & $0.207 / 0.834$ & $0.888 / 2.32$ & $1.40 / 1.94$ & $0.695 / 1.23$ & $0.801 / 0.926$ & $0.601 / 0.910$ \\
\hline & \multirow[t]{3}{*}{ Yincun Ditch $(n=9)$} & Range & $3.70-13.0$ & $248-11,425$ & $98.0-264$ & $37.0-189$ & $60.0-19,400$ & $27.0-336$ & $1.90-19.9$ & $84.0-2452$ \\
\hline & & Mean \pm SD & $9.00 \pm 3.40$ & $33,350 \pm 3551$ & $155 \pm 55.0$ & $107.0 \pm 63.8$ & $6402 \pm 6951$ & $153 \pm 113$ & $8.80 \pm 6.80$ & $895 \pm 783$ \\
\hline & & CV/Skewness & $0.379 /-0.618$ & $1.07 / 1.65$ & $0.354 / 1.06$ & $0.597 / 0.120$ & $1.09 / 0.898$ & 0.735/0.199 & $0.772 / 0.421$ & $0.874 / 0.947$ \\
\hline & TEC $^{\mathrm{c}}$ & & 9.79 & 990 & 43.4 & 31.6 & 180 & 35.8 & - & 121 \\
\hline & $\mathrm{PEC}^{\mathrm{C}}$ & & 33.0 & 4980 & 111 & 149 & 1060 & 128 & - & 459 \\
\hline
\end{tabular}

a Soil background values for heavy metals in Hebei Province, China (CNEMC, 1990).

${ }^{\mathrm{b}}$ Grade I/II guideline level for soil in China (GB 15618-1995) aims to protect the crop yield and public health (CMEP, 1995).

c TEC, threshold effect concentration; PEC, probable effect concentration (MacDonald et al., 2000).

It can be calculated using $I_{\text {geo }}=\log _{2}\left(C_{n} / 1.5 B_{n}\right)$, where $C_{n}$ is the measured concentration of the metal ions in soil, $B_{\mathrm{n}}$ is the geochemical background value of the corresponding metal and the coefficient 1.5 is used to detect very small anthropogenic influences (Muller, 1969). In this study, soil background values for heavy metals in Hebei Province, China (CNEMC, 1990), which are given in Table 1, were chosen as the geochemical reference values to calculate the $I_{\text {geo }}$ values.

According to Muller (1969), the corresponding relationships between $I_{\text {geo }}$ and the pollution level are as follows: unpolluted $\left(I_{\text {geo }}\right.$ $\leq 0)$, unpolluted to moderately polluted $\left(0<I_{\text {geo }} \leq 1\right)$, moderately polluted $\left(1<I_{\text {geo }} \leq 2\right)$, moderately to heavily polluted $\left(2<I_{\text {geo }}\right.$ $\leq 3)$, heavily polluted $\left(3<I_{\text {geo }} \leq 4\right)$, heavily to extremely polluted $\left(4<I_{\text {geo }} \leq 5\right)$, or extremely polluted $\left(I_{\text {geo }}>5\right)$. 


\subsection{Potential ecological risk index}

The potential ecological risk index method was developed by Håkanson (1980). In this study, the monomial potential ecological risk index (PERI) was used to assess the potential ecological risk of individual metals in soils and sediments. According to this methodology, the PERI of each heavy metal $\left(E_{r}^{i}\right)$ is defined as: $E_{r}^{i}=T_{r}^{i} \times C_{f}^{i}=T_{r}^{i} \times C_{0}^{i} / C_{n}^{i}$ where $T_{r}^{i}$ is the toxic response factor of each metal (e.g., $\mathrm{Hg}=40, \mathrm{Cd}=30, \mathrm{As}=\mathrm{Sb}=10, \mathrm{~Pb}=\mathrm{Cu}=5, \mathrm{Cr}=2$, $\mathrm{Zn}=1$ ) (Xu et al., 2008); $C_{f}^{i}$ is the contamination factor; $C_{0}^{i}$ is the concentration of each metal; and $C_{n}^{i}$ is the corresponding background value. In this study, the heavy metal content of soils in Hebei Province was used as the regional background value (CNEMC, 1990).

According to Håkanson (1980), the following $E_{r}^{i}$ values give an indication of ecological risk: $E_{r}^{i}<40$, low risk; $40 \leq E_{r}^{i}<80$, moderate risk; $80 \leq E_{r}^{i}<160$, considerable risk; $160 \leq E_{r}^{i}<320$, high risk; $E_{r}^{i} \geq 320$, very high risk.

\subsection{Health risk assessment}

In general, individuals are exposed to soil metals through three main pathways: ingestion, inhalation and dermal contact. According to the Exposure Factors Handbook (USEPA, 2001), the average daily doses (ADDs) through ingestion, dermal contact and inhalation for both adults and children were estimated. The human non-carcinogenic risk effects from metals can be assessed using the hazard quotient (HQ), which is the ratio of the ADD to the reference dose (RfD) of a heavy metal for the same exposure pathway (USEPA, 1989). If $\mathrm{HQ} \leq 1$, adverse health effects would be unlikely to be experienced, whereas potential non-carcinogenic effects would occur when HQ>1 (USEPA, 1989; Leung et al., 2007).

To assess the overall potential non-carcinogenic effects posed by many chemicals, the hazard index (HI) was calculated using the sum of HQ values of all chemicals in each site (assuming additive effects). For carcinogens, the ADDs were multiplied by the corresponding slope factor (SF, per $\mathrm{mg} \mathrm{kg}^{-1} \mathrm{day}^{-1}$ ) to produce a level of cancer risk (CR) (Wei et al., 2015). If multiple carcinogenic contaminants were present, the cancer risks from all carcinogens and exposure routes were summed (assuming additive effects). The acceptable or tolerable risk for regulatory purposes is within the range of $1.0 \times 10^{-6}-1.0 \times 10^{-4}$ (USEPA, 1989; Ferreira-Baptista and De Miguel, 2005).

The estimation methods and values of parameters used are shown in Tables S1 and S2, Supplementary information.

\section{Results and discussion}

\subsection{Heavy metals in soils}

The descriptive statistics of heavy metal concentrations in the soil samples from the plastic waste recycling area and reference area are summarized in Table 1 . While As and Sb are metalloids, an extensive definition of "heavy metal" is used in the present study to simplify the expression of the whole manuscript. In Zhaogezhuang and Daliu, the Kolmogorov-Smirnov (K-S) test indicated that $\mathrm{Cd}, \mathrm{Cr}, \mathrm{Cu}, \mathrm{Hg}, \mathrm{Pb}, \mathrm{Sb}$ and $\mathrm{Zn}$ had skewed concentration distributions and As had normal concentration distributions $(p>0.05)$. As shown in Table 1 , the concentrations of $\mathrm{Cd}, \mathrm{Cu}, \mathrm{Hg}$, $\mathrm{Pb}, \mathrm{Sb}$ and $\mathrm{Zn}$ varied widely and had relatively high coefficients of variation, suggesting that their inputs into soils in the study area might be, to a considerable degree, attributable to anthropogenic sources (Yongming et al., 2006). In the reference area, most of the metals had relatively narrow concentration ranges and low coefficients of variation, although only $\mathrm{As}, \mathrm{Cr}$ and $\mathrm{Zn}$ passed the $\mathrm{K}-\mathrm{S}$ test for normality $(p>0.05)$.

The mean concentrations of all metals, excluding arsenic, exceeded the corresponding natural background levels for Hebei Province. This was especially true for $\mathrm{Cd}, \mathrm{Hg}, \mathrm{Pb}$ and $\mathrm{Sb}$, which were about 4.45, 16.8, 1.88 and 2.51 times greater in Zhaogezhuang and 3.59, 5.87, 4.37 and 2.93 times greater in Daliu than their respective background values. In the soil quality standards of China, the Grade I level represents the average natural levels for uncontaminated soil, and Grade II can be used as the threshold values for protecting human health (CMEP, 1995). In this plastic recycling area, 61.5, 47.7, 29.2, 33.8 and $29.2 \%$ of soil samples for $\mathrm{Cd}$, $\mathrm{Cr}, \mathrm{Hg}, \mathrm{Pb}$ and $\mathrm{Zn}$, respectively, surpassed their corresponding Grade I values, whereas almost all samples for As and $\mathrm{Cu}$ were comparable to their Grade I values. In particular, approximately $33.8 \%$ of $\mathrm{Cd}$ samples and $12.3 \%$ of $\mathrm{Hg}$ samples exceeded their Grade II values. In contrast, the metal concentrations in soils from the reference area were generally comparable to their corresponding Grade I values, reflecting little influence from anthropogenic emissions of these metals. In the plastic recycling area, soils were contaminated with $\mathrm{Cd}, \mathrm{Hg}, \mathrm{Pb}$ and $\mathrm{Sb}$ and the pollution levels of $\mathrm{Cd}$ and $\mathrm{Hg}$ were relatively high.

A comparison of heavy metal concentrations in soils from Wen an with those from other regions is given in Table S3, Supporting information. The metal concentrations in the soils in our study were much lower than the concentrations found in soils from China's mining areas and from the e-waste recycling sites (Li et al. 2011; 2014; Luo et al., 2011; Zhang et al., 2014). Generally, Pb, Cd, $\mathrm{Cu}, \mathrm{Sb}$ and $\mathrm{Zn}$ were the most enriched metals in the soils in the e-waste recycling area (Song and Li, 2014). Differently, the pollutions of $\mathrm{Cu}$ and $\mathrm{Zn}$ were relatively lower in the study soils. The concentrations of $\mathrm{As}, \mathrm{Cr}, \mathrm{Cu}$ and $\mathrm{Zn}$ in the soils in the study area were comparable to concentrations observed in the soils from 31 cities in China (Cheng et al. 2014). However, the Cd, $\mathrm{Hg}, \mathrm{Pb}$ and $\mathrm{Sb}$ concentrations were 2-5 times higher than those found in the contaminated soils from the Chinese metropolises (Cheng et al., 2014). Compared with these areas, the surface soils in the plastic recycling area in Wen'an have suffered from moderate to high metal pollution.

To further characterize the soil metal pollution, the $I_{\text {geo }}$ values for heavy metals in the study soils were calculated and the results are described in Fig. 2(A). The $I_{\text {geo }}$ values of $\mathrm{Cd}, \mathrm{Hg}, \mathrm{Pb}$ and $\mathrm{Sb}$ varied the most, ranging from unpolluted to heavily or extremely polluted levels. In the plastic recycling area, the $I_{\text {geo }}$ values for $\mathrm{Cd}$ in 35.4 and $12.3 \%$ of samples, and for $\mathrm{Hg}$ in 40 and $23.1 \%$ of samples were larger than 1.0 and 2.0, respectively, suggesting that the soils were moderately to heavily polluted with $\mathrm{Cd}$ and $\mathrm{Hg}$. Approximately one fifth of samples were moderately polluted with $\mathrm{Pb}$ and $\mathrm{Sb}$ but there was no obvious geo-accumulation of other metals. Based on $I_{\text {geo }}$ values the reference area was not polluted with metals except for slight $\mathrm{Hg}$ pollution.

There were no significant Pearson's correlations between TOC and metals concentrations ( $p>0.05$ ), except for $\mathrm{Cr}$ and Sb. Several independent samples tests (Kruskal-Wallis $H$ ) showed that the concentrations of $\mathrm{Cd}, \mathrm{Cu}, \mathrm{Hg}$ and $\mathrm{Sb}$ were significantly different among Zhaogezhuang, Daliu and the reference area $(p<0.05)$, which suggested that different human activities had significant effects on the distribution of heavy metals in soils. The concentrations of $\mathrm{Cd}, \mathrm{Cu}, \mathrm{Pb}, \mathrm{Sb}$ and $\mathrm{Zn}$ in soils were significantly higher in the plastic recycling area than in the reference area $(p<0.05)$, as tested by the non-parametric test method (MannWhitney $U$ ). The mean levels of As and $\mathrm{Cr}$ were similar in the three sites and there were no significant differences $(p>0.05)$ in concentration distributions. Although the $p$ value (Mann-Whitney $U$ ) for $\mathrm{Hg}$ surpassed 0.05 , the mean levels of $\mathrm{Hg}$ were about eight 

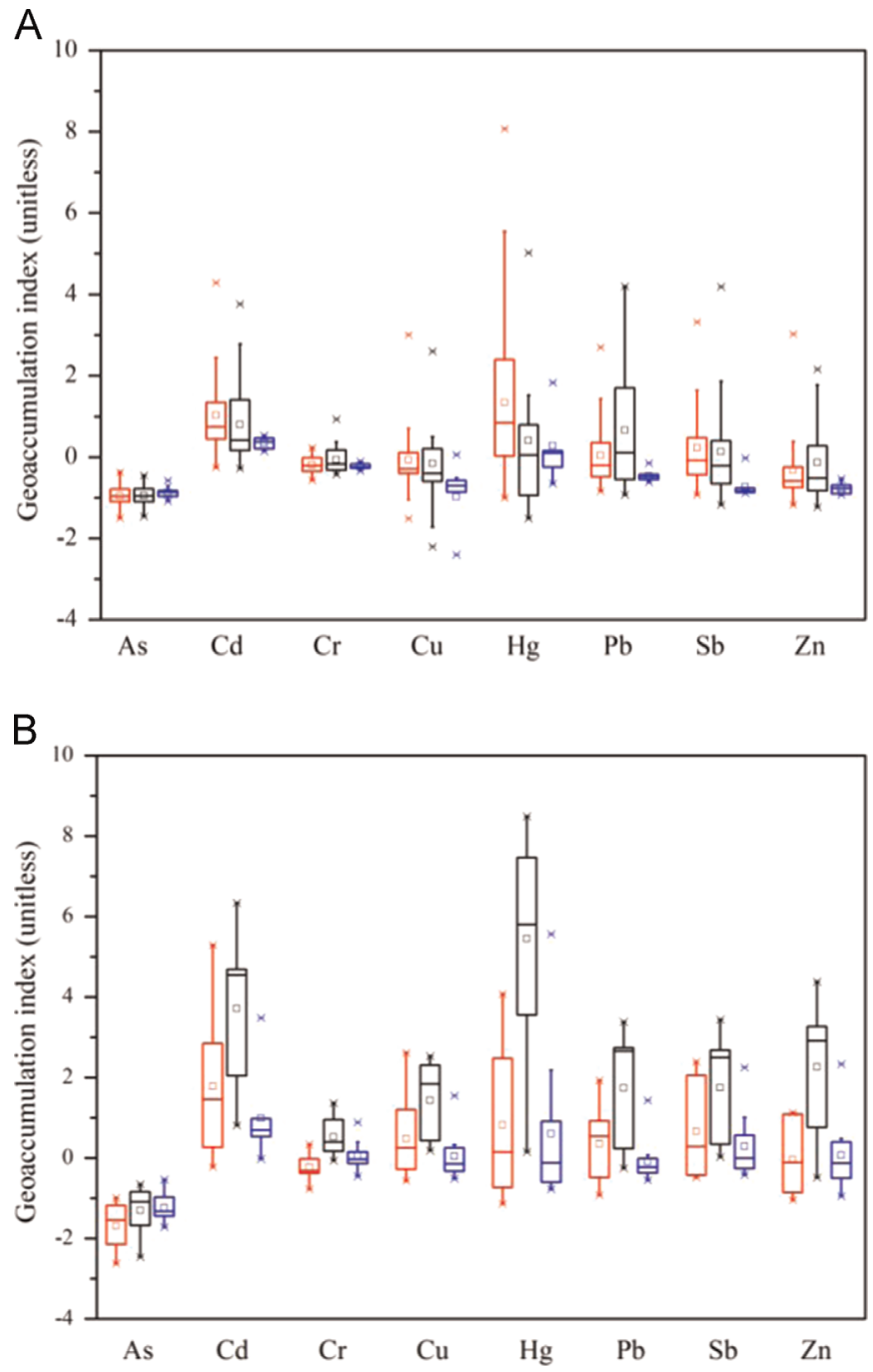

Fig. 2. Box plots of the geoaccumulation index for heavy metals in soils (A) from Zhaogezhuang (red), Daliu (black), Reference area (blue) and in sediments (B) from Renwen Canal (red), Yincun Ditch (black) and Xiaobaihe River (blue) in Wen'an, northern China. The lower and upper limits of the whiskers indicate 5\% and 95\% values, respectively; boxes extend from 25th to 75th percentiles; horizontal lines within the boxes represent medians; asterisks below or above the whiskers indicate outlier values. (For interpretation of the references to color in this figure legend, the reader is referred to the web version of this article.).

times greater in Zhaogezhuang and three times greater in Daliu than those in the reference area. In particular, extremely high $\mathrm{Hg}$ concentrations were found at sampling sites $Y_{43}\left(14.45 \mathrm{mg} \mathrm{kg}^{-1}\right)$, $Y_{13}\left(2.40 \mathrm{mg} \mathrm{kg}^{-1}\right)$ and $Y_{15}\left(2.52 \mathrm{mg} \mathrm{kg}^{-1}\right)$ in Zhaogezhuang and $\mathrm{D}_{8}\left(1.75 \mathrm{mg} \mathrm{kg}^{-1}\right)$ and $\mathrm{D}_{9}\left(1.19 \mathrm{mg} \mathrm{kg}^{-1}\right)$ in Daliu, where the intensive plastic waste recycling processes were active and had existed for more than a decade. The Hg levels in the soils were statistically significantly higher in Zhaogezhuang than in Daliu, which was perhaps related to the recycling history of the two towns (Tang et al., 2014).

\subsection{Heavy metals in sediments}

The basic statistics related to heavy metals in sediments from the three waterways were summarized in Table 1 . The metal concentrations of $\mathrm{As}, \mathrm{Cr}$ and $\mathrm{Pb}$ fit the normal distributions (K-S test, $p>0.05$ ) in the sediments from the Renwen Canal, while the concentrations of other metals presented skewed distributions in the three waterways. The heavy metals in surface sediments presented relatively wide concentration ranges and high coefficients of variation, implying that heavy metals could have been strongly influenced by anthropogenic inputs in the area.

The metal concentrations in sediments in this study were compared with those in other rivers, which are shown in Table S3. The $\mathrm{Cd}, \mathrm{Cu}, \mathrm{Pb}, \mathrm{Sb}$ and $\mathrm{Zn}$ concentrations in sediments from e-waste recycling areas were much higher than the concentrations found in sediments from the plastic recycling area in this study (Wang et al., 2009; Chen et al., 2010; Quan et al., 2014; Nie et al., 2015). However, the metal concentrations in the sediments in the study area were comparable to concentrations observed in sediments from the Lianjiang River, flowing across Guiyu where largescale e-waste dismantling activities have been conducted (Wang et al., 2009). The contamination levels of metals (excluding As) in the sediments from Wen'an were higher than those found in the sediments from the main river systems in China (Zhu and Wang, 2012).

In the studied sediments, the levels of all heavy metals (except As) were higher than their soil background values for Hebei Province (CNEMC, 1990); in particular, Cd and $\mathrm{Hg}$ were 15.3 and 54.7 times their background values, respectively. The sediment quality guidelines include a threshold effect concentration (TEC) and a probable effect concentration (PEC); below the TEC, adverse biological effects are rarely expected to occur whereas the PEC is defined as the level above which adverse biological effects are expected to occur more often than not (MacDonald et al., 2000). In this study, the concentrations of $\mathrm{Cr}$ in all samples, As and $\mathrm{Cd}$ in about one third of samples, $\mathrm{Hg}, \mathrm{Pb}$ and $\mathrm{Zn}$ in half of the samples, and $\mathrm{Cu}$ in $70.0 \%$ of samples exceeded the TECs. Moreover, $43.3 \%$ $(\mathrm{Cr})$, one fifth $(\mathrm{Hg}, \mathrm{Pb}$ and $\mathrm{Zn})$ and about $10 \%(\mathrm{Cd}$ and $\mathrm{Cu})$ of the samples had concentrations above their corresponding PECs. That is, adverse biological effects were probable because of the concentrations of these metals in the study sediments. This finding also suggests that further investigation of sources and ecological risk assessment of heavy metals is warranted.

The boxplots of the $I_{\text {geo }}$ values for the individual metals in the sediments are shown in Fig. 2(B). The $I_{\text {geo }}$ value of As was negative with no contamination in most sites. There was no or only very light $\mathrm{Cr}$ pollution in the study sediments. The $\mathrm{I}_{\text {geo }}$ values of $\mathrm{Pb}, \mathrm{Sb}$, $\mathrm{Cu}$ and $\mathrm{Zn}$ in sediments ranged from unpolluted to lightly unpolluted levels in the Xiaobaihe River and the Renwen Canal. In contrast, moderately to heavily polluted levels of $\mathrm{Pb}, \mathrm{Sb}, \mathrm{Cu}$ and $\mathrm{Zn}$ were found in the Yincun Ditch. The $I_{\text {geo }}$ values of $\mathrm{Cd}$ and $\mathrm{Hg}$ were relatively high and more than half of the total sediment samples were classified as moderately to heavily polluted. In particular, $I_{\text {geo }}$ values greater than 5 were recorded at some sites from the Renwen Canal and the Yincun Ditch for $\mathrm{Cd}$ and $\mathrm{Hg}$. This indicated that the accumulation of $\mathrm{Cd}$ and $\mathrm{Hg}$ was relatively serious in the sediments and that the metal contamination at some sites should be of concern.

Excluding As, the heavy metals in sediments presented significantly different concentration distribution trends in the three waterways (Kruskal-Wallis $H$ test, $p<0.05$ ). There was no statistically significant difference (Mann-Whitney $U$ test, $p>0.05$ ) in metal concentrations between the Renwen Canal and the Xiaobaihe River. High levels of seven metals were found in the sediments from the Yincun Ditch, which were significantly higher $(p<0.05)$ than those in the other two waterways. For example, the mean concentrations of $\mathrm{Cd}\left(3.34 \mathrm{mg} \mathrm{kg}^{-1}\right)$ and $\mathrm{Hg}\left(6.40 \mathrm{mg} \mathrm{kg}^{-1}\right)$ in the sediment from Yincun Ditch were almost 3-20 times higher than those in the other two waterways. Yincun Ditch was the key outlet of wastewater from the plastic recycling area, reflecting that the metal contamination was mainly derived from waste discharges from the waste plastic recycling facilities. On the other hand, relatively larger water volume and flow rate might influence the metal accumulation in sediments from the Renwen Canal and the Xiaobaihe River. 
A

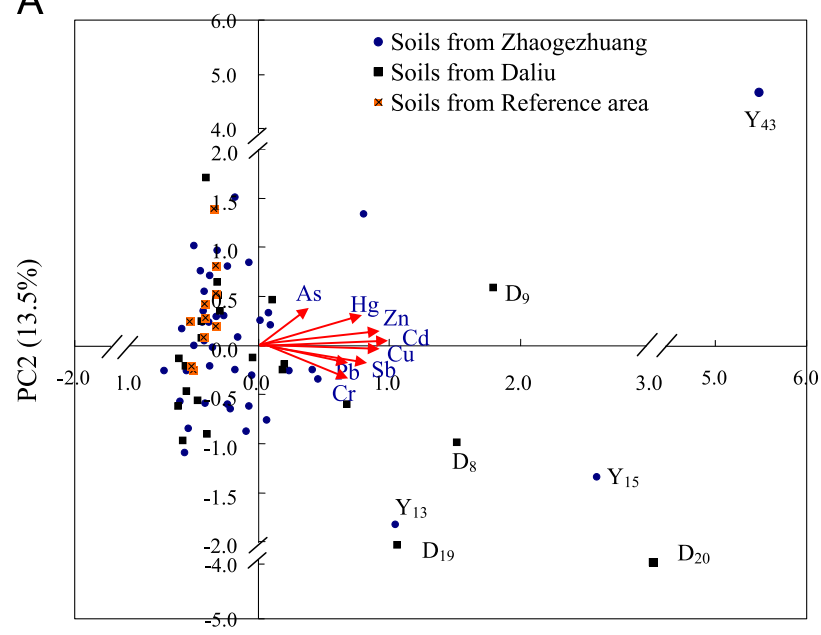

PC1 (59.3\%)

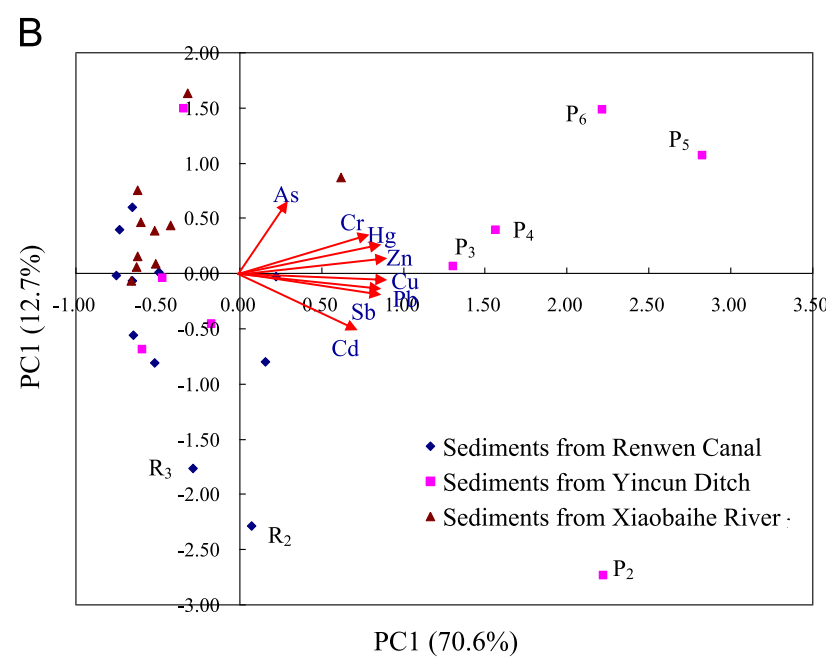

Fig. 3. Biplots of soil samples (A), sediment samples (B) and heavy metal concentrations, produced from principal component analysis.

\subsection{Source identification of heavy metals}

Principal component analysis (PCA) was conducted on the metal concentrations in soils to identify the possible sources of the eight metals. The results of the Kaiser-Meyer-Olkin test $(\mathrm{KMO}=0.824)$ and Bartlett's test of sphericity $(p<0.001)$ indicated that metal concentrations were suitable for PCA. All the heavy metals were well represented by principal component 1 (PC1) and principal component 2 ( $\mathrm{PC} 2$ ), which accounted for $72.8 \%$ of the total variance. In the loading plot of PCA shown in Fig. 3(A), two groups were identified. $\mathrm{Zn}, \mathrm{Cu}, \mathrm{Cd}, \mathrm{Sb}, \mathrm{Cr}, \mathrm{Hg}$ and $\mathrm{Pb}$ formed a group, which showed similar loading for both principal components, indicating that they were likely to be mainly from the same source. A second group consisted only of As, which had a higher loading in PC2.

Various metals are used in different plastics as additives or filling materials (Dimitrakakis et al., 2009; Li and Shi, 2011; Nakashima et al., 2012; Rochman et al., 2013). These additives include pigments (e.g., $\mathrm{ZnO}$ and $\mathrm{Cr}_{2} \mathrm{O}_{3}$ ), flame retardants (often brominated organics combined with $\mathrm{Sb}_{2} \mathrm{O}_{3}$ ) and stabilizers or plasticizers (e.g., compounds of $\mathrm{Cd}, \mathrm{Pb}$ and $\mathrm{Zn}$ ) (Morf et al., 2007; Li and Shi, 2011). The amounts and types of metal compounds applied to plastic products constantly increase, because a range of different properties are achieved by the incorporation of these metal compounds (Yu et al., 2008; Kotori et al., 2012). Some metals are also used as catalysts during plastic syntheses, particularly Sb and Hg (Cheng et al., 2010; Kotori et al., 2012). Hg compounds are customarily applied as decoration or coating in plastic products such as plastic toys (Sun, 2005; Guney and Zagury, 2012). Some plastics from WEEE could contain or be contaminated by $\mathrm{Hg}$ and its compounds that are normally used in fluorescent lamps, relays, or temperature switches in electric and electronic equipment ( $\mathrm{Li}$ and Shi, 2011; Ni et al., 2014). High metal levels in plastic wastes have been reported in many previous studies (Soares et al., 2005; Morf et al., 2007; Dimitrakakis et al., 2009; Stenvall et al., 2013). For example, the $\mathrm{Cd}$ concentrations were up to $761 \mathrm{mg} \mathrm{kg}^{-1}$ and Sb concentrations ranged from 1.7 to $21.7 \mathrm{mg} \mathrm{kg}^{-1}$ in some metallized plastic wastes (Soares et al., 2005). Lead was detected at levels up to $200 \mathrm{mg} \mathrm{kg}^{-1}$ in the recyclable waste plastics from the WEEE (Stenvall et al., 2013). Santos et al. also reported 4-12 $\mathrm{mg} \mathrm{kg}^{-1}$ of $\mathrm{Hg}$ in WEEE plastics (Santos et al., 2011). These heavy metals could be released during uncontrolled plastic waste recycling activities, particularly during milling, washing and extrusion, and become a major contributor of heavy metals to the environment. These facts suggested that the $\mathrm{Zn}, \mathrm{Cu}, \mathrm{Cd}, \mathrm{Sb}, \mathrm{Cr}, \mathrm{Hg}$ and $\mathrm{Pb}$ contents that were represented by $\mathrm{PC} 1$ were related to the discharge from plastic waste recycling.

The contamination pattern was further studied with Pearson's correlation analyses. The concentration of As was not significantly correlated with any of the other heavy metals in soils, as shown in Table S4. The other seven metals were positively correlated among each other at $p<0.01$, excluding $\mathrm{Pb}$ and $\mathrm{Hg}$ that were significantly positively correlated at $p<0.05$, suggesting that these elements had almost the same source. PBDEs are a class of pollutants characteristic of plastic waste recycling because of their extensive usage as flame retardants in plastic products (Leung et al., 2007; Tang et al., 2014). Correlations between concentrations of metals and PBDEs were analyzed based on our previously published data (Tang et al., 2014). There was no significant correlation between As and PBDEs. $\mathrm{Zn}, \mathrm{Cu}, \mathrm{Cd}, \mathrm{Sb}, \mathrm{Cr}, \mathrm{Hg}$ and $\mathrm{Pb}$ were all significantly correlated with the major components of technical penta-, octaand/or deca-BDE products at $p<0.05$. In particular, significant positive correlations $(p<0.01)$ were found between all seven metals and BDE-209, the predominant congener, contributing an average of about $90 \%$ of the $\mathrm{SPBDE}$ concentrations in surface soils (Tang et al., 2014). These results intensively supported that conclusion that heavy metals in the soils were mainly derived from plastic waste recycling.

Most of the studied sites coordinated near the origin of the PCA plot (Fig. 3(A)), which represented the mean concentrations of all sampling sites (Zhao et al., 2014). Sites from the plastic waste recycling area had a scattering concentration trend along the right direction of PC1, reflecting the main influence from waste plastic recycling activities. Sites $\mathrm{Y}_{13}, \mathrm{Y}_{15}$ and $\mathrm{Y}_{43}$ from Zhaogezhuang and $\mathrm{D}_{8}, \mathrm{D}_{9}, \mathrm{D}_{19}$ and $\mathrm{D}_{20}$ from Daliu, with high levels of $\mathrm{Hg}$ and $\mathrm{Cd}$, could be easily recognized among all of the sampling sites. The metal emissions from the low-tech plastic waste recycling methods used in such sites could have caused the high metal concentrations found in those soil samples. However, some sites from both the plastic recycling and the reference area had relatively higher loading in PC2, which might imply pollution from municipal wastewater irrigation or other agricultural sources (Wang et al., 2014).

PCA was also used to identify the sources of heavy metal contamination in the sediments $(\mathrm{KMO}=0.788$; Bartlett's sphericity tests at $p<0.001$ ), and the results are shown in Fig. 3(B). The first two components explained $83.3 \%$ of the total variance in the metal concentrations in the sediment samples, and the PC1 and PC2 loading plots were similar to those for the soils. PC1 was dominated by $\mathrm{Zn}, \mathrm{Cu}, \mathrm{Cd}, \mathrm{Sb}, \mathrm{Cr}, \mathrm{Hg}$ and $\mathrm{Pb}$. The concentrations of the 
seven metals were significantly correlated with one another, except for $\mathrm{Hg}$ and $\mathrm{Cr}$ (Table S5), suggesting that these elements had common sources. Similar to the soil samples, the sediment metal concentrations were significantly positively correlated, in general, with those of the major components of technical penta-, octaand/or deca-BDE products (Tang et al., 2014). These results showed that the seven metals in the sediments mostly originated from waste plastic recycling. Of particular note is that $\mathrm{Cd}$ had a relatively high negative loading in PC2, implying that $\mathrm{Cd}$ in the sediments likely had other sources. Arsenic had a high positive loading in PC2, which was similar to the result from the soils. From the Pearson's correlation matrix (Table S5), no significant correlations were found between As and the other metals or PBDEs, indicating a specific source for As. The sources for arsenic might be geochemical and/or anthropogenic rather than originating from plastic recycling.

The plot of PC1 versus PC2 scores calculated for each sediment sample was shown in Fig. 3(B). Nearly all of the sediments from the Xiaobaihe River, half of the sediments from the Renwen Canal and a few of the sediments from the Yincun Ditch had low scores in both PC1 and PC2 and grouped together distinctly at the left corner of the figure, suggesting the occurrence of moderate pollution at these locations. The other sites from the Yincun Ditch displayed high scores in PC1, such as sites $\mathrm{P}_{2}, \mathrm{P}_{3}, \mathrm{P}_{4}, \mathrm{P}_{5}$ and $\mathrm{P}_{6}$, which clearly contained the highest concentrations of $\mathrm{Hg}$ and $\mathrm{Cd}$, indicating the major influence of the metals derived from wastewater discharges from the waste plastic recycling facilities. Other seriously polluted sites, such as $R_{2}, R_{3}$ and $P_{2}$, were clearly separated on the PC1 axis. At these sites, large quantities of municipal wastewater are discharged without treatment. The loading plots of these sites in PC2 might imply that heavy metals in the sediments were also related to the municipal wastewater discharge.

\subsection{Risk characteristics of contamination}

Potential ecological risks related to heavy metals in the study soils were calculated and the $E_{r}^{i}$ values of individual elements are described in Fig. 4(A). In the reference area, the $E_{r}^{i}$ values for $\mathrm{As}, \mathrm{Cr}$, $\mathrm{Cu}, \mathrm{Pb}, \mathrm{Sb}$ and $\mathrm{Zn}$ were less than 40 and for $\mathrm{Cd}$ and $\mathrm{Hg}$ were less than 80 in most samples, implying low potential ecological risk. In the plastic recycling area, the $E_{r}^{i}$ values for $\mathrm{As}, \mathrm{Cr}, \mathrm{Cu}$ and $\mathrm{Zn}$ ranged within the low risk levels. The $E_{r}^{i}$ of $\mathrm{Pb}$ and $\mathrm{Sb}$ were generally low, while the $E_{r}^{i}$ of $\mathrm{Sb}$ was greater than 80 in several sites. The mean $E_{r}^{i}$ values for $\mathrm{Cd}$ and $\mathrm{Hg}$ were 125 and 523, respectively, much higher than those of the other metals. About 40.0 and $52.3 \%$ of the sites had $E_{r}^{i}$ values greater than 80 for $\mathrm{Cd}$ and $\mathrm{Hg}$, respectively. In particular, about one sixth of samples based on Cd contamination and one third of samples based on $\mathrm{Hg}$ contamination were classified as high risk in the plastic recycling area.

The $E_{r}^{i}$ values for metals in the sediments and their ecological risk levels are described in Fig. 4(B). Low $E_{r}^{i}$ values for $\mathrm{As}, \mathrm{Cr}, \mathrm{Cu}$ and $\mathrm{Zn}$ were observed for the three study waterways. The $E_{r}^{i}$ values for $\mathrm{Pb}$ and $\mathrm{Sb}$ ranged from low to moderate levels, with half of the sites in the Yincun Ditch showing considerable risks for Sb. The $E_{r}^{i}$ values for $\mathrm{Cd}$ and $\mathrm{Hg}$ ranged from moderate to very high risk for almost all sampling sites. In the Xiaobai River, sites $\mathrm{X}_{6}$ and $\mathrm{X}_{8}$ were classified as very high ecological risk. About one third of the sites in the Renwen Canal and $77.8 \%$ of the samples from the Yincun Ditch were classified as causing a very high potential ecological risk because of their $\mathrm{Cd}$ and $\mathrm{Hg}$ concentrations. The sediment pollution by $\mathrm{Cd}$ and $\mathrm{Hg}$ and their potential ecological risks should be of great concern.

In this study, the non-carcinogenic health risks to adults and children from exposure to soil metals in the plastic waste recycling area were estimated and the results are shown in Table 2 . The non-
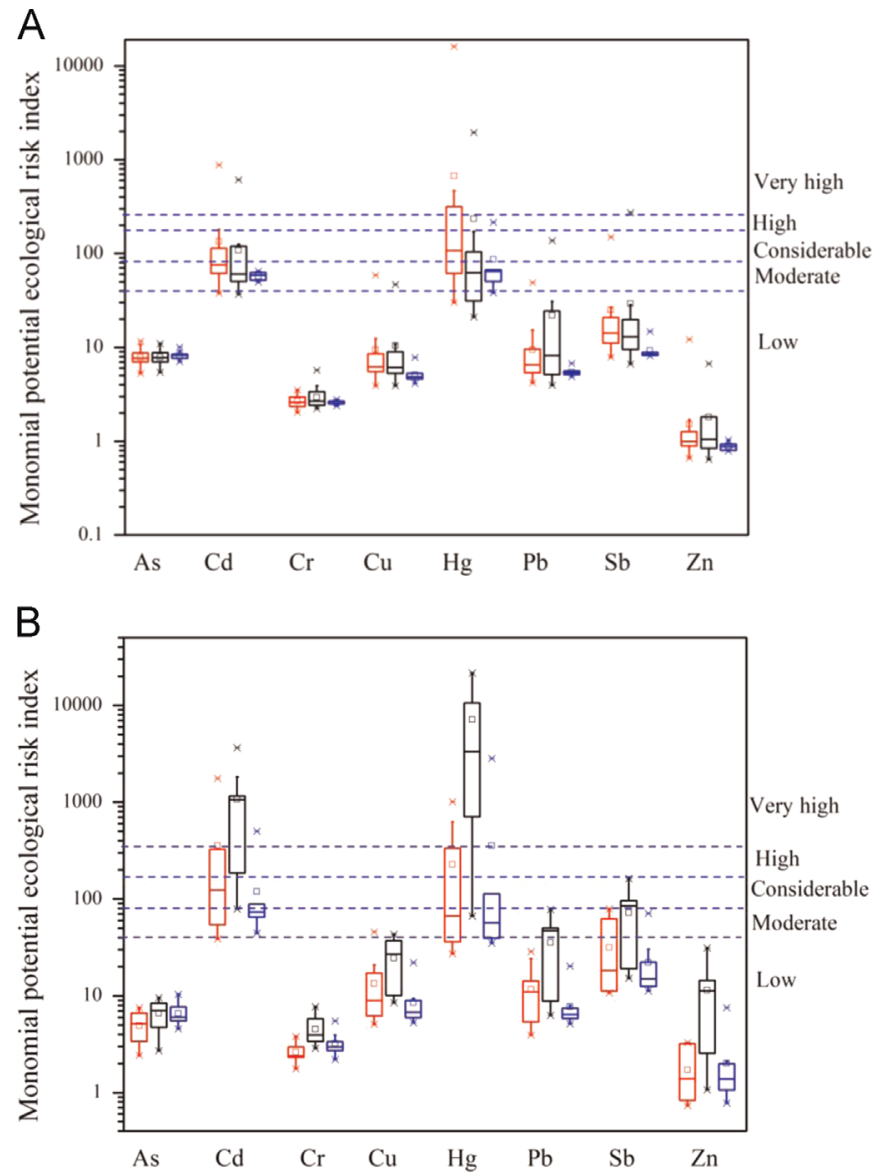

Fig. 4. Monomial potential ecological risk index $\left(E_{r}^{i}\right)$ for heavy metals in soil (A) and sediment (B) from the waste plastic recycling area. Contamination classes: $E_{r}^{i}<40$, low risk; $40 \leq E_{r}^{i}<80$, moderate risk; $80 \leq E_{r}^{i}<160$, considerable risk; $160 \leq E_{r}^{i}<320$, high risk; $E_{r}^{i} \geq 320$, very high risk, using the method developed by Håkanson (1980).

carcinogenic health risks were not calculated in the reference area, because of the relatively low levels of metals in the soils. For adults, the total exposure $\mathrm{HI}$ from ingestion, dermal contact, and inhalation for all of the eight metals generally ranged from 0.20 to 1.0. The HI was higher than 1.0 in only $3.1 \%$ of soils indicating that there would be, in general, no potential human health risks to adults in this area. For children the total hazard quotients of $\mathrm{Cd}, \mathrm{Pb}$ and $S b$ were $2.01,1.11$, and 1.88 , respectively, at the 95th percentile. The combined HI values from the eight heavy metals exceeded 1 for almost all of the soils in the plastic recycling area. The mean total exposure HI from the eight metals was 2.19 and the combined $\mathrm{HI}$ was 5.07 at the 95th percentile, indicating a high potential non-carcinogenic risk to the local children. Children are more susceptible to a given dose of toxin and are likely to inadvertently ingest significant quantities of soil by virtue of their pica behavior and hand or finger sucking (Rasmussen et al., 2001). Therefore, there might be significant non-carcinogenic risks to the local population associated with soil in the plastic recycling area.

In the plastic recycling area, the carcinogenic risks of As and $\mathrm{Cd}$ in the soils were estimated through the three exposure modes and those of $\mathrm{Cr}$ were considered only via inhalation because of the lack of corresponding carcinogenic slope factors. In the plastic recycling area, the total carcinogenic risk values for the three metals ranged from $9.94 \times 10^{-6}$ to $2.25 \times 10^{-5}$ (mean, $1.43 \times 10^{-5}$ ) for adults and from $1.45 \times 10^{-5}$ to $3.27 \times 10^{-5}$ (mean, $2.09 \times 10^{-5}$ ) for children, which were within the acceptable levels based on USEPA guidelines (USEPA, 1989). The majority of the carcinogenic risk values for both adults and children were between $1.0 \times 10^{-5}$ and 
Table 2

Non-carcinogenic risks for adults and children because of environmental exposure to soil metals in Wen'an, northern China.

\begin{tabular}{|c|c|c|c|c|c|c|}
\hline & \multicolumn{3}{|l|}{ Adults } & \multicolumn{3}{|l|}{ Children } \\
\hline & 5th percentile & Median & 95th percentile & 5th percentile & Median & 95th percentile \\
\hline As & 0.065 & 0.091 & 0.127 & 0.447 & 0.625 & 0.869 \\
\hline $\mathrm{Cd}$ & 0.024 & 0.043 & 0.389 & 0.125 & 0.221 & 2.01 \\
\hline $\mathrm{Cr}$ & 0.040 & 0.048 & 0.066 & 0.319 & 0.380 & 0.525 \\
\hline $\mathrm{Cu}$ & 0.003 & 0.004 & 0.030 & 0.016 & 0.025 & 0.174 \\
\hline $\mathrm{Hg}$ & 0.001 & 0.003 & 0.095 & 0.006 & 0.019 & 0.552 \\
\hline $\mathrm{Pb}$ & 0.011 & 0.018 & 0.154 & 0.080 & 0.130 & 1.11 \\
\hline $\mathrm{Sb}$ & 0.021 & 0.037 & 0.331 & 0.118 & 0.209 & 1.88 \\
\hline $\mathrm{Zn}$ & 0.001 & 0.001 & 0.004 & 0.004 & 0.005 & 0.028 \\
\hline Total & 0.181 & 0.255 & 0.859 & 1.21 & 1.67 & 5.07 \\
\hline
\end{tabular}

$2.0 \times 10^{-5}$, which were higher than $1.0 \times 10^{-6}$, showing a requirement for pollution control based on the carcinogenic risk of soil metals.

Our results confirmed that exposure to toxic metals from soils and sediments would cause high potential ecological risks and health risks in this area, although the results would inevitably be affected by the inherent uncertainty in risk assessment (USEPA, 1989; Cao et al., 2015). In this study, bioavailability of the metals in soils and sediments was not considered, which might result in an overestimation of the potential risks. However, the risks might be underestimated if synergistic harmful effects on humans and other organisms occurred with the coexisting metal pollution in soils and sediments. This study has shown that poorly controlled material recycling of plastic wastes is a significant source of heavy metals to the environment and further research on risk assessments and risk controls are warranted.

\section{Acknowledgments}

This research was supported by the National Environmental Protection Public Welfare Science and Technology Research Program of China (201309023), the National Natural Science Foundation of China (No. 41571445), and the Fundamental Research Funds for the Central Universities (No. 15MS60).

\section{Appendix A. Supplementary information}

Supplementary data associated with this article can be found in the online version at http://dx.doi.org/10.1016/j.ecoenv.2015.08. 006.

\section{References}

Al-Salem, S.M., Lettieri, P., Baeyens, J., 2009. Recycling and recovery routes of plastic solid waste (PSW): a review. Waste Manag. 29 (10), 2625-2643. http://dx.doi. org/10.1016/j.wasman.2009.06.004.

Cao, S., Duan, X., Zhao, X., Wang, B., Ma, J., Fan, D., Sun, C., He, B., Wei, F., Jiang, G., 2015. Health risk assessment of various metal(loid)s via multiple exposure pathways on children living near a typical lead-acid battery plant, China. Environ. Pollut. 200, 16-23. http://dx.doi.org/10.1016/j.envpol.2015.02.010.

CGS (China Geological Survey), 2009. Draft of Geochemical Survey Specification (1:50000). CGS, Beijing. (In Chinese).

Chen, L., Yu, C., Shen, C., Zhang, C., Liu, L., Shen, K., Tang, X., Chen, Y., 2010. Study on adverse impact of e-waste disassembly on surface sediment in East China by chemical analysis and bioassays. J. Soils Sediments 10, 359-367. http://dx.doi. org/10.1007/s11368-009-0176-8.

Cheng, H.X., Li, M., Zhao, C.D., Li, K., Peng, M., Qin, A.H., Cheng, X.M., 2014. Overview of trace metals in the urban soil of 31 metropolises in China. J. Geochem. Explor. 139, 31-52. http://dx.doi.org/10.1016/j.gexplo.2013.08.012.

Cheng, X., Shi, H., Adams, C.D., Ma, Y., 2010. Assessment of metal contaminations leaching out from recycling plastic bottles upon treatments. Environ. Sci. Pollut. Res. 17 (7), 1323-1330. http://dx.doi.org/10.1007/s11356-010-0312-4.
CMEP (Chinese Ministry of Environmental Protection), 1995. Environmental Quality Standard for Soils (GB15618-1995). CMEP, Beijing. (In Chinese)

CMEP (Chinese Ministry of Environmental Protection), 2010. Draft of Guidelines for Environmental Monitoring of Contaminated Sites. CMEP, Beijing. (In Chinese).

CNEMC (China National Environmental Monitoring Center), 1990. The Soil Background Value in China. China Environmental Science Press, Beijing. (In Chinese).

Dimitrakakis, E., Janz, A., Bilitewski, B., Gidarakos, E., 2009. Determination of heavy metals and halogens in plastics from electric and electronic waste. Waste Manag. 29 (10), 2700-2706. http://dx.doi.org/10.1016/j.wasman.2009.05.020.

Ferreira-Baptista, L., De Miguel, E., 2005. Geochemistry and risk assessment of street dust in Luanda, Angola: a tropical urban environment. Atmos. Environ. 39 (25), 4501-4512. http://dx.doi.org/10.1016/j.atmosenv.2005.03.026.

Guney, M., Zagury, G.J., 2012. Heavy metals in toys and low-cost jewelry: critical review of US and Canadian legislations and recommendations for testing. Environ. Sci. Technol. 46 (8), 4265-4274. http://dx.doi.org/10.1021/es203470x.

Håkanson, L., 1980. An ecological risk index for aquatic pollution control. a sedimentological approach. Water Res. 14 (8), 975-1001. http://dx.doi.org/10.1016 0043-1354(80)90143-8.

He, Z., Li, G., Chen, J., Huang, Y., An, T., Zhang, C., 2015. Pollution characteristics and health risk assessment of volatile organic compounds emitted from different plastic solid waste recycling workshops. Environ. Int. 77, 85-94. http://dx.doi. org/10.1016/j.envint.2015.01.004.

Hopewell, J., Dvorak, R., Kosior, E., 2009. Plastics recycling: challenges and opportunities. Philos. Trans.: R. Soc. Lond. B Biol. Sci. 364 (1526), 2115-2126. http: //dx.doi.org/10.1098/rstb.2008.0311.

Huang, D.-Y., Zhou, S.-G., Hong, W., Feng, W.-F., Tao, L., 2013. Pollution characteristics of volatile organic compounds, polycyclic aromatic hydrocarbons and phthalate esters emitted from plastic wastes recycling granulation plants in Xingtan Town, South China. Atmos. Environ. 71, 327-334. http://dx.doi.org/ 10.1016/j.atmosenv.2013.02.011.

Jambeck, J.R., Geyer, R., Wilcox, C., Siegler, T.R., Perryman, M., Andrady, A., Narayan, R., Law, K.L., 2015. Marine pollution. Plastic waste inputs from land into the ocean. Science 347 (6223), 768-771. http://dx.doi.org/10.1126/science.1260352.

Kotori, P., Beqiraj, A., Cullap, A., Beqiraj, E., 2012. Distribution of mercury in contaminated zones and rehabilitation of the PVC hot spot in Vlora. J. Environ. Prot. Ecol. 13 (1), 86-95.

Leung, A.O., Luksemburg, W.J., Wong, A.S., Wong, M.H., 2007. Spatial distribution of polybrominated diphenyl ethers and polychlorinated dibenzo-p-dioxins and dibenzofurans in soil and combusted residue at Guiyu, an electronic waste recycling site in southeast China. Environ. Sci. Technol. 41 (8), 2730-2737. http: //dx.doi.org/10.1021/es0625935.

Li, J., Duan, H., Shi, P., 2011. Heavy metal contamination of surface soil in electronic waste dismantling area: site investigation and source-apportionment analysis. Waste Manag. Res. 29 (7), 727-738. http://dx.doi.org/10.1177/ $0734242 X 10397580$.

Li, Z., Ma, Z., van der Kuijp, T.J., Yuan, Z., Huang, L., 2014. A review of soil heavy metal pollution from mines in China: pollution and health risk assessment. Sci. Total Environ. 468-469, 843-853. http://dx.doi.org/10.1016/j. scitotenv.2013.08.090

Lithner, D., Larsson, A., Dave, G., 2011. Environmental and health hazard ranking and assessment of plastic polymers based on chemical composition. Sci. Total Environ. 409 (18), 3309-3324. http://dx.doi.org/10.1016/j.scitotenv.2011.04.038.

Liu, H.L., 2011. Wen'an: when will the confusion leading to "pointless exposure" end? The situation in the Wen'an waste plastics industry after public concern. Environ. Conserv. 2011 (Z1), 77-80.

Luo, C., Liu, C., Wang, Y., Liu, X., Li, F., Zhang, G., Li, X., 2011. Heavy metal contamination in soils and vegetables near an e-waste processing site, South China. J. Hazard. Mater. 186, 481-490. http://dx.doi.org/10.1016/j.jhazmat.2010.11.024.

MacDonald, D.D., Ingersoll, C.G., Berger, T.A., 2000. Development and evaluation of consensus-based sediment quality guidelines for freshwater ecosystems. Arch. Environ. Contam. Toxicol. 39 (1), 20-31. http://dx.doi.org/10.1007/ s002440010075.

Morf, L.S., Tremp., J., Gloor, R., Schuppisser, F., Stengele, M., Taverna, R., 2007. Metals, non-metals and PCB in electrical and electronic waste-actual levels in Switzerland. Waste Manag. 27 (10), 1306-1316. http://dx.doi.org/10.1016/j. 
wasman.2006.06.014

Muller, G., 1969. Index of geoaccumulation in sediments of the Rhine River. GeoJournal 2 (3), 108-118.

Nakashima, E., Isobe, A., Kako, S., Itai, T., Takahashi, S., 2012. Quantification of toxic metals derived from macroplastic litter on Ookushi Beach, Japan. Environ. Sci. Technol. 46 (18), 10099-10105. http://dx.doi.org/10.1021/es301362g.

Ni, W., Chen, Y., Huang, Y., Wang, X., Zhang, G., Luo, J., Wu, K., 2014. Hair mercury concentrations and associated factors in an electronic waste recycling area, Guiyu, China. Environ. Res. 128, 84-91. http://dx.doi.org/10.1016/j. envres.2013.10.005.

Nie, X., Fan, C., Wang, Z., Su, T., Liu, X., An, T., 2015. Toxic assessment of the leachates of paddy soils and river sediments from e-waste dismantling sites to microalga, Pseudokirchneriella subcapitata. Ecotoxicol. Environ. Saf. 111, 168-176. http: //dx.doi.org/10.1016/j.ecoenv.2014.10.012.

Pacheco, E.B.A.V., Ronchetti, L.M., Masanet, E., 2012. An overview of plastic recycling in Rio de Janeiro. Resour. Conserv. Recycl. 60, 140-146. http://dx.doi. org/10.1016/j.resconrec.2011.12.010.

Quan, S.X., Yan, B., Lei, C., Yang, F., Li, N., Xiao, X.M., Fu, J.M., 2014. Distribution of heavy metal pollution in sediments from an acid leaching site of e-waste. Sci. Total Environ 499, 349-355. http://dx.doi.org/10.1016/j.scitotenv.2014.08.084.

Rasmussen, P.E., Subramanian, K.S., Jessiman, B.J., 2001. A multi-element profile of house dust in relation to exterior dust and soils in the city of Ottawa, Canada. Sci. Total Environ. 267 (1-3), 125-140. http://dx.doi.org/10.1016/S0048-9697 (00)00775-0.

Rochman, C.M., Browne, M.A., Halpern, B.S., Hentschel., B.T., Hoh., E., Karapanagioti, H.K., Rios-Mendoza, L.M., Takada., H., Thompson R.C., S., 2013. Policy: classify plastic waste as hazardous. Nature 494 (7436), 169-171. http://dx.doi.org/ 10.1038/494169a.

Santos, M.C., Nóbrega, J.A., Cadore, S., 2011. Determination of Cd, Cr, $\mathrm{Hg}$ and $\mathrm{Pb}$ in plastics from waste electrical and electronic equipment by inductively coupled plasma mass spectrometry with collision-reaction interface technology. J. Hazard. Mater. 190 (13), 833-839. http://dx.doi.org/10.1016/j.jhazmat.2011.04.004.

Soares, E.P., Saiki, M., Wiebeck, H., 2005. Determination of inorganic constituents and polymers in metallized plastic materials. J. Radioanal. Nucl. Chem. 264 (1) 9-13. http://dx.doi.org/10.1007/s10967-005-0667-z.

Song, Q., Li, J., 2014. Environmental effects of heavy metals derived from the e-waste recycling activities in China: a systematic review. Waste Manag. 34, 2587-2594. http://dx.doi.org/10.1016/j.wasman.2014.08.012.

Stenvall, E., Tostar, S., Boldizar, A., Foreman, M.R., Möller, K., 2013. An analysis of the composition and metal contamination of plastics from waste electrical and electronic equipment (WEEE). Waste Manag. 33 (4), 915-922. http://dx.doi.org/ 10.1016/j.wasman.2012.12.022.

Sun, C., 2005. Study on the Migration Behavior of Environmental Estrogens From Toys, thesis. Sichuan University, Chengdu, China, pp. 19-29.

Tang, Z., Huang, Q., Cheng, J., Yang, Y., Yang, J., Guo, W., Nie, Z., Zeng, N., Jin, L., 2014 Polybrominated diphenyl ethers in soils, sediments, and human hair in a plastic waste recycling area: a neglected heavily polluted area. Environ. Sci. Technol. 48 (3), 1508-1516. http://dx.doi.org/10.1021/es404905u.

Thompson, R.C., Moore, C.J., vom Saal, F.S., Swan, S.H., 2009. Plastics, the environment and human health: current consensus and future trends. Philos. Trans. R. Soc. Lond. B Biol. Sci. 364 (1526), 2153-2166. http://dx.doi.org/10.1098/ rstb.2009.0053.
Tsai, C.J., Chen., M.L., Chang, K.F., Chang, F.K., Mao, I.F., 2009. The pollution characteristics of odor, volatile organochlorinated compounds and polycyclic aromatic hydrocarbons emitted from plastic waste recycling plants. Chemosphere 74 (8), 1104-1110. http://dx.doi.org/10.1016/j.chemosphere.2008.10.041.

USEPA, 1989. Risk Assessment Guidance for Superfund. Human Health Evaluation Manual (Part A) vol. 1. Office of Emergency and Remedial Response, Washington, DC ([EPA/540/1-89/002]).

USEPA, 2001. Child-Specic Exposure Factors Handbook. EPA-600-P-00-002B. National Center for Environmental Assessment.

Wang, F., Leung, A.O., Wu, S.C., Yang, M.S., Wong, M.H., 2009. Environ. Pollut. 157, 2082-2090. http://dx.doi.org/10.1016/j.envpol.2009.02.015.

Wang, Z., Yao, L., Liu, G., Liu, W., 2014. Heavy metals in water, sediments and submerged macrophytes in ponds around the Dianchi Lake, China. Ecotoxicol. Environ. Saf. 107, 200-206. http://dx.doi.org/10.1016/j.ecoenv.2014.06.002.

Wei, T., Zhang, Y., 2014. China's plastic waste recycling industry to be revolutionary changed: a "Post-Hedge-Action" era in China's plastic recycling industry. Chin. Packag. Ind. 9, 46-55, In chinese.

Wei, X., Gao, B., Wang, P., Zhou, H., Lu, J., 2015. Pollution characteristics and health risk assessment of heavy metals in street dusts from different functional areas in Beijing, China. Ecotoxicol. Environ. Saf. 112. http://dx.doi.org/10.1016/j. ecoenv.2014.11.005 186-92.

Xu, G.F., Li, G.J., Fan, L., 2010. Solid waste management based on circular economy theory: a case study in Wen'an, Heibei Province. Environ. Sci. Technol. 33 (6E), 506-508.

Xu, Z., Ni, S., Tuo, X., Zhang, C., 2008. Calculation of heavy metals' toxicity coefficient in the evaluation of potential ecological risk index. Environ. Sci. Technol. 31 (2), 112-115. http://dx.doi.org/10.3969/j.issn.1003-6504.2008.02.030.

Yang, J., Buekens, A., 2014. Recycling of WEEE plastics: a review. J. Mater. Cycles Waste Manag. 16, 415-434. http://dx.doi.org/10.1007/s10163-014-0241-2.

Yang, Z., Wang, Y., Shen, Z., Niu, J., Tang, Z., 2009. Distribution and speciation of heavy metals in sediments from the mainstream, tributaries, and lakes of the Yangtze River catchment of Wuhan, China. J. Hazard. Mater. 166 (2-3), 1186-1194. http://dx.doi.org/10.1016/j.jhazmat.2008.12.034.

Yongming, H., Peixuan, D., Junji, C., Posmentier, E.S., 2006. Multivariate analysis of heavy metal contamination in urban dusts of Xi'an, Central China. Sci. Total Environ. 355 (1-3), 176-186. http://dx.doi.org/10.1016/j.scitotenv.2005.02.026.

Yu, X.Z., Zennegg, M., Engwall, M., Rotander, A., Larsson, M., Wong, M.H., Weber, R., 2008. E-waste recycling heavily contaminates a Chinese city with chlorinated, brominated and mixed halogenated dioxins. Organohalogen Compd. 70, 813-816.

Zhang, Q., Ye, J., Chen, J., Xu, H., Wang, C., Zhao, M., 2014. Risk assessment of polychlorinated biphenyls and heavy metals in soils of an abandoned e-waste site in China. Environ. Pollut. 185, 258-265. http://dx.doi.org/10.1016/j. envpol.2013.11.003.

Zhao, L., Xu, Y., Hou, H., Shangguan, Y., Li, F., 2014. Source identification and health risk assessment of metals in urban soils around the Tanggu chemical industrial district, Tianjin, China. Sci. Total Environ. 468-469, 654-662. http://dx.doi.org/ 10.1016/j.scitotenv.2013.08.094.

Zhu, Q.Q., Wang, Z.L., 2012. Distribution characteristics and source analysis of heavy metals in sediments of the main river systems in China. Earth Environ. 40, 305-313. http://dx.doi.org/10.14050/j.cnki.1672-9250.2012.03.001. 